\title{
INTERVENÇÃO ARQUEOLÓGICA DE 2014 NA CITÂNIA DE BRITEIROS (GUIMARÃES). ALGUNS DADOS E PROBLEMÁTICAS SOBRE O URBANISMO DOS OPPIDA
}

\section{ARCHAEOLOGICAL EXCAVATIONS AT CITÂNIA DE BRITEIROS (GUIMARÃES), 2014. SOME DATA AND ISSUES REGARDING THE URBANISM OF THE OPPIDA}

\author{
Gonçalo Passos Correia da CRuz \\ Laboratório de Paisagens, Património e Território da Universidade do Minho \\ (Lab2pt) \\ Sociedade Martins Sarmento \\ goncalo.cruz@msarmento.org
}

JosÉ Luís FerReira ANTUNES

Laboratório de Paisagens, Património e Território da Universidade do Minho (Lab2pt)

Sociedade Martins Sarmento

jose.antunes@msarmento.org

Recibido: 01/11/2017

Aceptado: 27/04/2018

RESUMEN: Las excavaciones arqueológicas del año 2014 en el castro de la Citânia de Briteiros se desarrollaron en torno a un complejo habitacional familiar descubierto durante los trabajos desarrollados en el siglo XIX. Los sondeos arqueológicos abarcaron un patio y espacios interiores de esta casa familiar, así como también una calle pública. El registro estratigráfico y los datos cronológicos y funcionales obtenidos en esta campaña permiten plantear un interesante debate en relación con el urbanismo de los grandes castros, conocidos como oppida, así como también acerca de los conceptos asociados a la arquitectura doméstica en torno al cambio de Era, cuando dio comienzo el proceso de Romanización.

PALABRAS CLAVE: Citânia de Briteiros, castro, oppida, arquitectura doméstica, romanización

ABSTRACT: The 2014 archaeological campaign in the hillfort of Citânia de Briteiros was developed around a family compound discovered during the 19 th century fieldworks. The archaeological trenches included a courtyard and indoor spaces of this family house, as well as a public road. The stratigraphic sample and the chronological and functional data obtained in these fieldworks enable an interesting discussion around the urbanism of the 
large hillforts, known as oppida, as well as the concepts regarding domestic architecture by the transition of Era, when the Romanization process begun.

KEYWORDS: Citânia de Briteiros, hillfort, oppida, domestic architecture, Romanization

\section{INTRODUÇÃO}

Os trabalhos arqueológicos que se têm vindo a realizar, de forma descontínua, na Citânia de Briteiros, desde 2005, obedecem a objetivos precisos, nomeadamente a atualização da informação histórica do monumento, intervencionado desde o século XIX e exposto, por assim dizer, a diferentes orientações metodológicas que acabaram por transformar o sítio arqueológico num campo de experimentação. Se esta particularidade fez da Citânia de Briteiros um monumento sobejamente conhecido e com uma considerável área intervencionada, fez também com que, praticamente até 2005, a interpretação da estação arqueológica se resumisse às conceções oitocentistas de Martins Sarmento, subscritas quase na íntegra por Mário Cardozo² ${ }^{2}$ responsável pelo monumento durante mais de quarenta anos.

Foi, em boa hora, identificada a ineficácia e as insuficiências de uma interpretação desatualizada, associada a um sítio classificado como Monumento Nacional desde 1910 e aberto ao público desde 1934. Não se tinha formulado um quadro evolutivo para a ocupação do sítio arqueológico em diferentes períodos ou diferentes fases. Não se considerava o povoado proto-histórico como apenas um momento, embora quiçá o mais relevante, da utilização do monte de S. Romão. Não existiam trabalhos arqueológicos especificamente orientados para a definição funcional dos espaços e para a aferição dos momentos fundacionais de diferentes estruturas. Por último, não se tinha ainda pensado a interpretação deste local de forma articulada com as intervenções e os trabalhos académicos entretanto desenvolvidos para sítios arqueológicos coetâneos. Pese embora muitos aspetos que permanecem em aberto, a evolução material e cultural da Idade do Ferro constitui já um discurso científico significativamente consolidado ${ }^{3}$, o que pode auxiliar e informar uma reinterpretação da Citânia de Briteiros.

1 LEMOS. F. CRUZ, G. (2005-06). “Trabalhos arqueológicos na Citânia de Briteiros. Campanhas de 2005 e 2006 ”. Revista de Guimarães, 115/116,pp. 11-50; LEMOS. F. CRUZ, G. (2006). "Citânia de Briteiros. Programa de Investigação e Valorização do Monumento”. Fórum, 39; LEMOS. F. CRUZ, G. (2007). "Citânia de Briteiros: trabalhos arqueológicos recente”. Al-Madan Online / Adenda Electrónica. II ${ }^{\text {a }}$ Série, 15, VI, pp. 31-36; CRUZ, G. ANTUNES, J. (2010). “Citânia de Briteiros. Notícia dos trabalhos arqueológicos (2007-2010)”. Revista de Guimarães, 119/120.

2 CARDozo, M. (1996). Citânia de Briteiros e Castro de Sabroso. Notícia descritiva. Guimarães: Sociedade Martins Sarmento.

3 MARTINS, M. (1990): O Povoamento Proto-histórico e a Romanização da Bacia do Curso Médio do Cávado. 
Pese embora o facto de as intervenções arqueológicas mais recentes terem tido início há 10 anos, não se concretizaram ainda grande parte dos objetivos, tendo sido possível, no entanto, uma revisão substancial do que se pode considerar uma "interpretação oficial", veiculada pela Sociedade Martins Sarmento, acerca da Citânia, que tem sido difundida a um volume considerável de visitantes e de público escolar. A este facto não está alheia a criação do Museu do Solar da Ponte, que tem sido a natural plataforma interpretativa da Citânia, ideia que esteve, aliás, subjacente à sua criação. Devemos aqui referir que as intervenções arqueológicas realizadas até à data na Citânia de Briteiros, iniciadas e acompanhadas pelos investigadores da Universidade do Minho, Francisco Sande Lemos e Maria Manuela Martins, e executadas pelos signatários desta comunicação, com o apoio da Universidade, têm tido um carácter pontual, não contínuo.

Desde 2005, os trabalhos realizados na Citânia consistiram em sete campanhas anuais, nas quais foram realizadas catorze sondagens localizadas, abrangendo uma área aproximada de $180 \mathrm{~m} 2$, num total de 185 dias de trabalho. Uma amostragem reduzida, portanto, mas que ainda assim proporcionou um volume considerável de informação, que nos permitiu atingir algumas conclusões quanto às dinâmicas de um sítio arqueológico com uma ocupação diacrónica ampla e de estratigrafia particularmente complexa.

Um aspeto fundamental que norteia as intervenções arqueológicas na Citânia de Briteiros é o facto, verificado logo em 2005, de a área convencionada como "escavada", e que corresponderá a menos de metade da área total do monumento, não estar escavada até à rocha. Ou seja, a tendência seguida por Martins Sarmento, e ainda mais por Mário Cardozo, foi a de "escavar até encontrar ruínas". As escavações antigas puseram a descoberto as estruturas atualmente visíveis, mas raramente afetaram os seus níveis fundacionais. Em situações ocasionais, Sarmento dava indicações aos trabalhadores para abrirem uma vala abaixo de um piso, por exemplo, para verificar a ocorrência de achados interessantes, ou para localizar o substrato geológico. Estas valas são perfeitamente visíveis no registo arqueológico, como se verificou na sondagem 100B, em $2006^{4}$ e na sondagem 97V, conforme descreveremos adiante.

Cadernos de Arqueologia. Série Monografias. Braga: Unidade de Arqueologia da Universidade do Minho; GONZÁLEZ-RUIBAL, A. (2006-07): Galaicos. Poder y Comunidad en el Noroeste de la Península Ibérica (1200 a.C. - 50 d.C.). Brigantium, 18-19. A Coruña: Museo Arqueológico e Histórico da Coruña; AYÁN VILA, X. (2013). "Todo queda en casa: espacio doméstico, poder y división social en la Edad del hierro del NW de la Península Ibérica”. En Gutiérrez, S. y Grau, I. (eds). De la estructura doméstica al espacio social. Lecturas arqueológicas del uso social del espacio. Alicante: Publicaciones Universidad de Alicante, pp. 39-56.

4 LEMOS. F. CRUZ, G. (2005-06). “Trabalhos arqueológicos na Citânia de Briteiros...”, p. 19. 
Este critério, no entanto, não foi exatamente seguido no que diz respeito aos alinhamentos de muralha intervencionados por Mário Cardozo. Com efeito, uma parte das muralhas foi restaurada no século XX recorrendo não apenas aos derrubes, mas também ao material pétreo removido das valas de fundação, conforme a descrição do próprio Mário Cardozo ${ }^{5}$, fator já anteriormente anotado por Alfredo González-Ruibal ${ }^{6}$.

No entanto, a prática adotada na maior parte da área intervencionada, teve como resultado, por um lado, a quase total remoção de níveis de abandono e boa parte dos níveis de ocupação das estruturas visíveis, mas, por outro, a preservação da maior parte dos níveis de fundação dessas mesmas estruturas, bem como níveis de ocupação anteriores. Este fator revelou-se particularmente interessante, possibilitando assim a "recuperação" de informação estratigráfica, existente em níveis arqueológicos selados. É certo que em praticamente todas as campanhas se escavaram níveis do século XIX: camadas de revolvimento, com um registo material extremamente fragmentado, correspondentes a escombreiras subsequentes aos desaterros de Sarmento e Cardozo, que ainda hoje fazem parte do cenário do monumento. No entanto, a própria escavação destas escombreiras tem revelado alguns resultados, como veremos adiante.

\section{CONTEXTUALIZAÇÃO DA CAMPANHA DE 2014}

A projeção dos locais nos quais foram abertas sondagens arqueológicas partiu de uma seleção criteriosa, privilegiando pontos com maiores expectativas de potência estratigráfica, locais que aparentem menor incidência de escavações antigas e pontos próximos de estruturas visíveis, tendo como objetivo a identificação de valas de fundação que possam, assim, atestar o momento de construção ou reparação de estruturas arqueológicas anteriormente postas a descoberto.

Dos pontos previamente definidos, as escavações realizadas incidiram apenas numa área relativamente restrita (Figura 1) em relação à amplitude geográfica pretendida, que irá proporcionar uma amostragem mais abrangente do sítio que, como sabemos, atinge dimensões excecionais para um povoado proto-histórico do Noroeste de Portugal.

5 CARDOZO, M. (1949). “Escavações na Citânia de Briteiros. Relatório da campanha de 1949”. Revista de Guimarães, 59 (3-4), pp. 408-410.

6 GONZÁleZ-RUIBAL, A. (2006-07): Galaicos. Poder y Comunidad en el Noroeste..., op.cit., p. 35. 


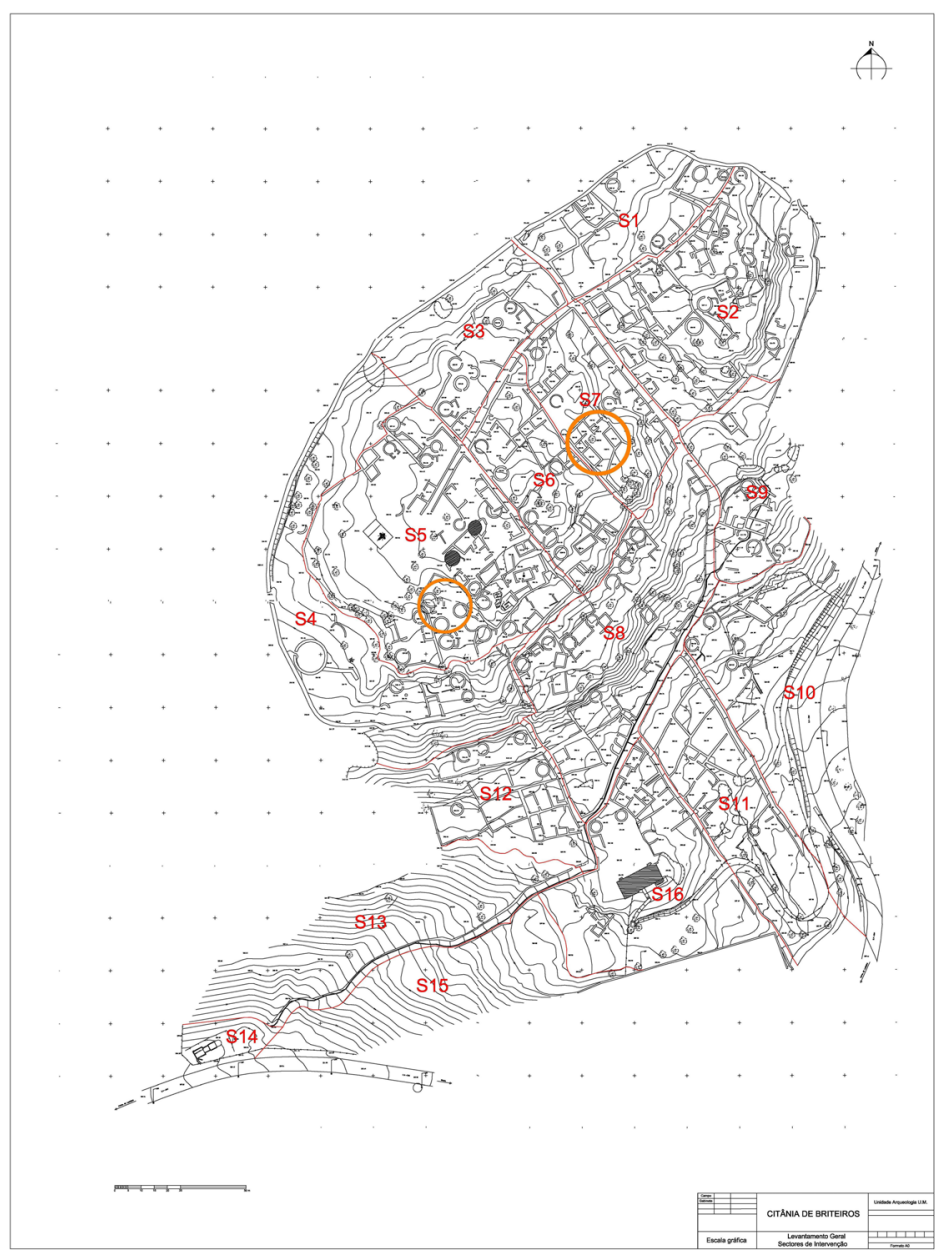

Figura 1. Planta da área escavada da Citânia de Briteiros, com divisão dos sectores de estudo. Os círculos indicam a "Casa da Espiral", à esquerda (sector 5) e a "Casa de Avscvs", à direita (sector 7). Levantamento da Infotop. Vectorização da Unidade de Arqueologia da UM.

Um outro critério seguido nas campanhas desta última década foi a ideia de estudar comparativamente duas unidades domésticas com características arquitetónicas distintas, designadamente um complexo familiar formado apenas por construções circulares e um outro formado exclusivamente por construções angulares, o que 
se usa chamar um conjunto "de tipo domvs" . Ainda que esta diferença possa não corresponder necessariamente a distintos períodos de construção, a opção por cânones arquitetónicos completamente diferentes terá subjacente uma distinta visão do espaço, da funcionalidade e do conforto por parte dos seus construtores. Implica mesmo uma nova ideia de casa, em relação aos conjuntos formados por construções redondas características do mundo dos castros.

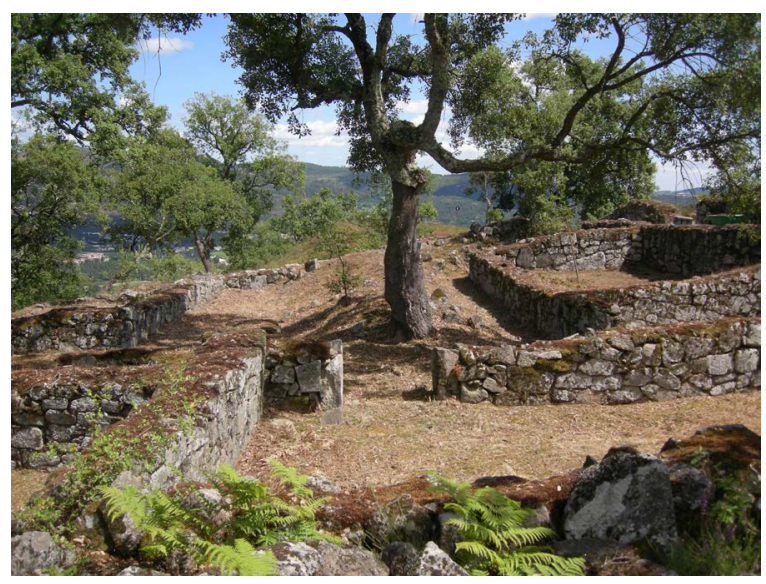

Figura 2. Vista parcial da "Casa de Avscvs" (Unidade Habitacional 3, do Sector 7), antes do início dos trabalhos. Fotografia de 2008.

Os dois exemplos selecionados são duas unidades familiares conhecidas como “Casa da Espiral” (Unidade Habitacional 12, Sector 5), intervencionada nas campanhas de 2005 a 2008, e "Casa de Avscvs” (Unidade Habitacional 3, Sector 7), na qual se realizaram intervenções entre 2008 e $2010^{9}$, e em 2014. As duas unidades domésticas, localizadas em diferentes quarteirões, foram construídas na acrópole do oppidum, ou seja, na zona mais central do povoado. A Unidade Habitacional 12, no Sector 5, corresponde à área de habitação cognominada de "Casa da Espiral”, no seguimento da identificação de uma gravura rupestre num elemento arquitetónico disposto no pátio. Neste complexo habitacional familiar foram numeradas quatro estruturas, das quais três grandes casas circulares, uma delas com vestíbulo, ocupando um lugar central no pátio da residência. O cuidado e o pormenor patentes na conceção do lajeado deste pátio (que ocuparia a quase totalidade da área descoberta da unidade doméstica) e

GONZÁLEZ-RUIBAL, A. (2006-07): Galaicos. Poder y Comunidad en el Noroeste..., op.cit., p. 378.

8 LEMOS. F. CRUZ, G. (2005-06). “Trabalhos arqueológicos na Citânia de Briteiros...”; CRUZ, G. ANTUNES, J. (2010). “Citânia de Briteiros. Notícia...”, op.cit.

9 CRUZ, G. ANTUNES, J. (2010). “Citânia de Briteiros. Notícia...”, op.cit. 
no aparelho construtivo reticulado da estrutura central, assim como a implantação do complexo no centro nevrálgico do povoado (a poucos metros da "Casa do Conselho"), indicam a proeminência desta casa de família no contexto urbano da Citânia.

Pelo que já referimos, a "Casa de Avscvs" (Figuras 2 e 3) foi, assim, definida como uma área estratégica do ponto de vista das escavações arqueológicas por se tratar de um caso atípico em relação à arquitetura doméstica que prolifera no povoado e por confrontar diretamente com um dos arruamentos ortogonais do oppidum, sendo portanto um ponto particularmente interessante para se analisar a relação entre o traçado e construção das ruas e a construção e utilização das unidades familiares, em momentos distintos. Uma terceira razão que justificou a intervenção neste espaço é o facto de o pátio interior da "Casa de Avscvs" ter sido, na sua maior parte, ocupado por uma escombreira resultante das escavações do século XIX (Figura 4). Se em alguns pontos do monumento se torna praticamente impossível apurar a proveniência das terras das escavações antigas, as terras desta escombreira provêm, sem grandes dúvidas, dos níveis de ocupação e de abandono dos compartimentos que rodeiam o pátio. Este fator pode, de facto, auxiliar, de forma relativa, uma datação da utilização desta casa, em função dos materiais arqueológicos existentes no aterro central.

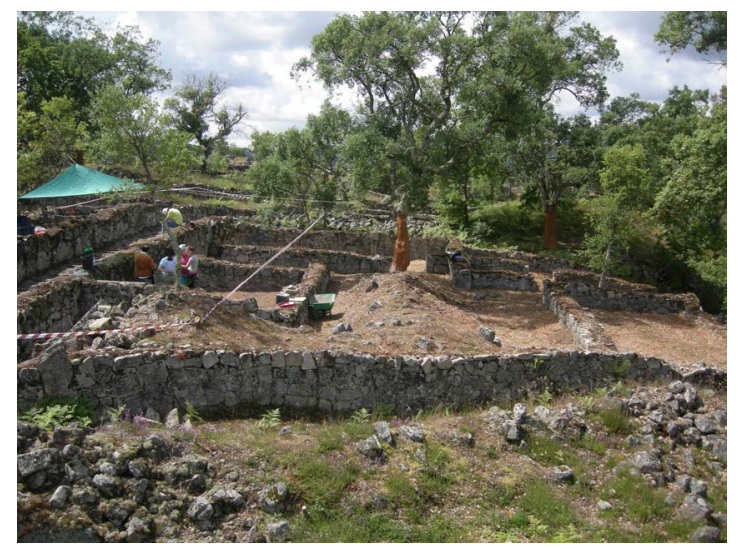

Figura 3. Vista de conjunto da "Casa de Avscvs", durante os trabalhos de 2008.

Colocou-se desde logo, como abordagem prévia, uma velha questão que concerne à arquitetura doméstica nos castros: a dicotomia entre casas circulares e casas retangulares e a classificação destas últimas como uma importação ou inovação resultante dos contactos com o mundo romano. Procurando desviar as nossas reflexões de premissas pré-estabelecidas, como a que acabámos de referir, não partimos do princípio de que iríamos fazer escavações numa “casa romana”, mas que 
iríamos desenvolver os nossos trabalhos num espaço doméstico de um povoado protohistórico para o qual procurávamos uma definição cronológica mais precisa e uma, se possível, clarificação de espaços funcionais. Este afastamento prévio em relação a uma definição digamos que "tradicional" prende-se com a discussão, ainda pertinente, da cronologia das construções de planta retangular, das quais se conhecem exemplares comprovadamente construídos na Idade do Ferro ${ }^{10}$. Está também relacionada com esta questão a existência, igualmente comprovada, de casas oblongas ou "retangulares com cantos arredondados" em contextos anteriores ao período romano Alto-imperial.

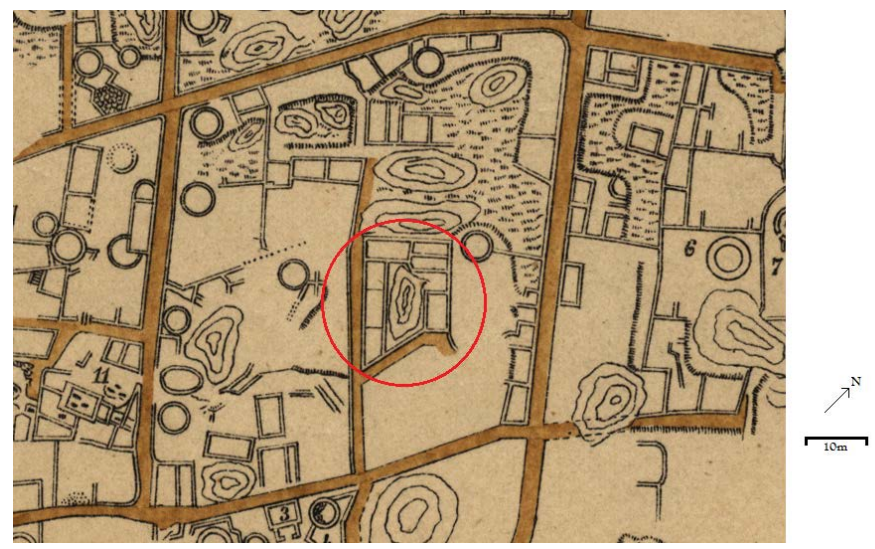

Figura 4. Representação da "Casa de Avscvs" no levantamento topográfico de 1892 (da autoria de Álvaro de Castelões), no qual se registou o aterro cobrindo o pátio interior. Original na Biblioteca Nacional de Portugal.

Foram escavadas três sondagens nesta área específica da acrópole, com a denominação correspondente à malha de escavações: 97T, 97V e 99V (Figura 5). A escavação/finalização destas duas últimas sondagens constitui o mais relevante trabalho desenvolvido na campanha de $2014^{11}$. Os resultados da sondagem 97T, concluída em 2009, foram já anteriormente publicados ${ }^{12}$. Aberta numa área parcialmente exterior à

${ }^{10}$ RODRÍGUEZ MARTÍNEZ, R.. ABOAL FERNÁNDEZ, R. CASTRO HIERRO, V. CANCELA CEREIJO, C. AYÁN VILA, X. (2011). “Una posible factoría prerromana en el Noroeste. Primeras valoraciones de la intervención en el Campo de A Lanzada (Sanxenxo, Pontevedra)”. Férvedes: Revista de Investigación, nº 7, pp. 159-168; AYÁN VILA, X. (2013). “Todo queda en casa: espacio doméstico...”, op.cit.; LÓPEZ MARCOS, M. ÁLVAREZ GONZÁLEZ, Y. LÓPEZ GONZÁLEZ, L. F. (2011). “Arquitectura defensiva en el Castro de Castromaior (Lugo). Análisis de las técnicas constructivas en el acceso al recinto central del poblado”. Arqueología de la Arquitectura, 8, pp. 47-63.

11 Deixamos aqui o nosso reconhecimento aos estudantes de Arqueologia da Universidade do Minho, Diana Rocha, Saúl Sendas, Isac Valente, Nuno Oliveira, Israel Grando e Daniela Januário, e ao estudante voluntário Guillem Domingo, pela sua preciosa colaboração nos trabalhos de 2014.

12 CRUZ, G. ANTUNES, J. (2010). “Citânia de Briteiros. Notícia...”, op.cit.; CRUZ, G. (2015). “O surgimento do espaço urbano no Noroeste da Ibéria. Uma reflexão sobre os oppida pré-romanos”. En Martínez Peñín, R. y Cavero 
unidade doméstica que constitui aqui o objeto de estudo, e abrangendo o troço da via pública que daria acesso à casa, a sondagem permitiu concluir que o traçado original da rua é anterior ao conjunto familiar, tendo sido construído na primeira metade do século I a. C.. A casa teria sido então, à partida, edificada em momento posterior, informação aferida a partir da identificação de um alteamento do pavimento lajeado da rua.

Resumiremos, em seguida, os resultados das sondagens que foram terminadas em 2014.

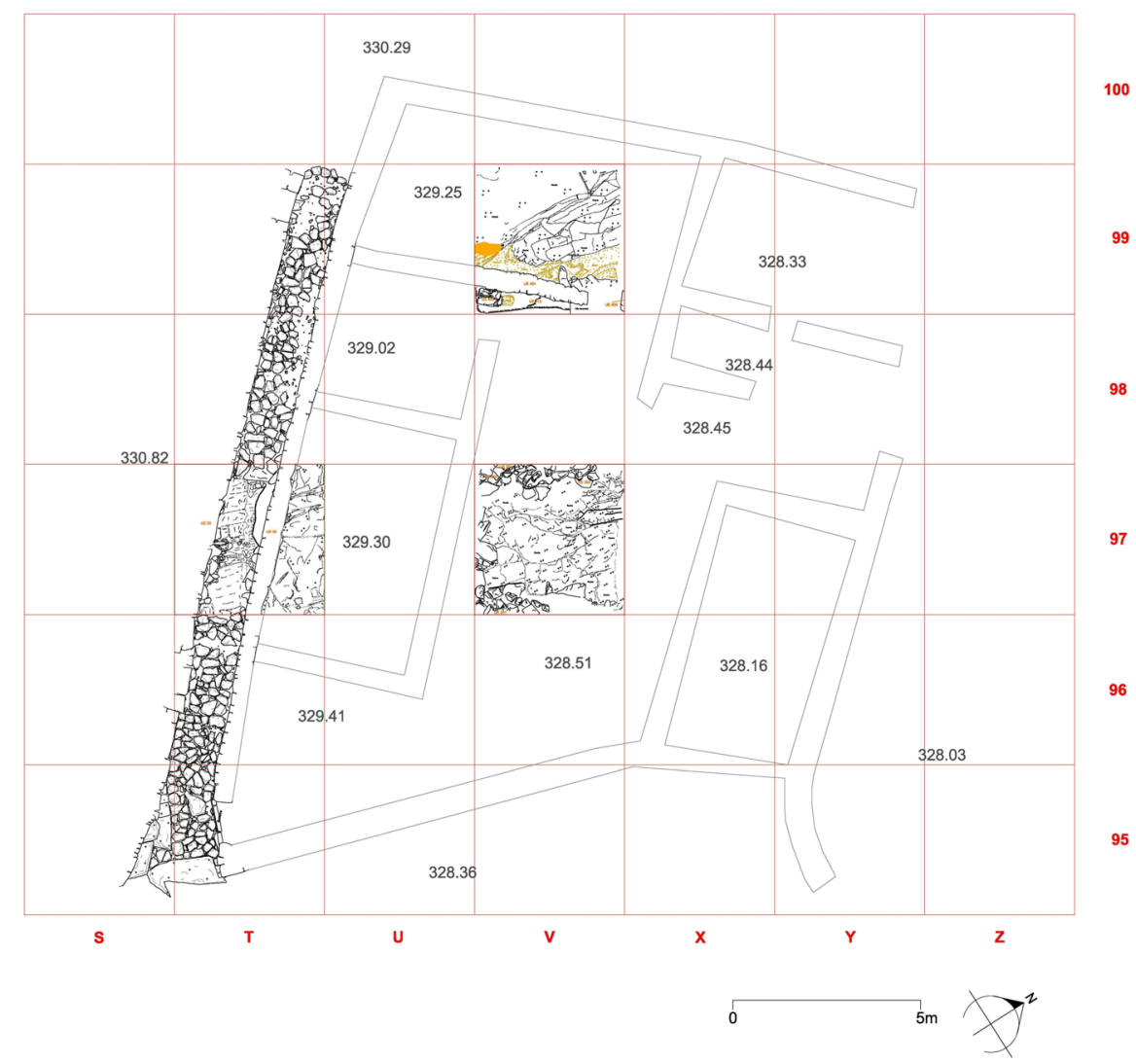

Figura 5. Delimitação das sondagens $97 \mathrm{~T}, 97 \mathrm{~V}$ e 99V, abertas na área da "Casa de Avscus". Distingue-se, no limite Noroeste do conjunto doméstico, o desenho do pavimento da rua, efetuado nos trabalhos de 2008.

Domínguez, G. (eds). Evolución de los espacios urbanos y sus territorios en el Noroeste de la Península Ibérica. León: Instituto de Estudios Medievales de la Universidad de León, Unidade de Arqueologia da Universidade do Minho, pp. 403-424. 


\section{RESULTADOS DAS SONDAGENS 97V E 99V}

A sondagem 97V foi aberta no interior da área atribuível a um possível pátio interior centralizado, abrangendo um largo troço do já referido aterro do século XIX. Por ordem de escavação, foram registadas cinco grandes atividades do ponto de vista estratigráfico:

a) $\mathrm{O}$ aterro (Figura 6) resultante das escavações do século XIX (representado pelas UE’s 200, 201 e 202), com materiais muito fragmentados que incluíam cerâmica da Idade do Ferro e cerâmica romana, de diversas tipologias;

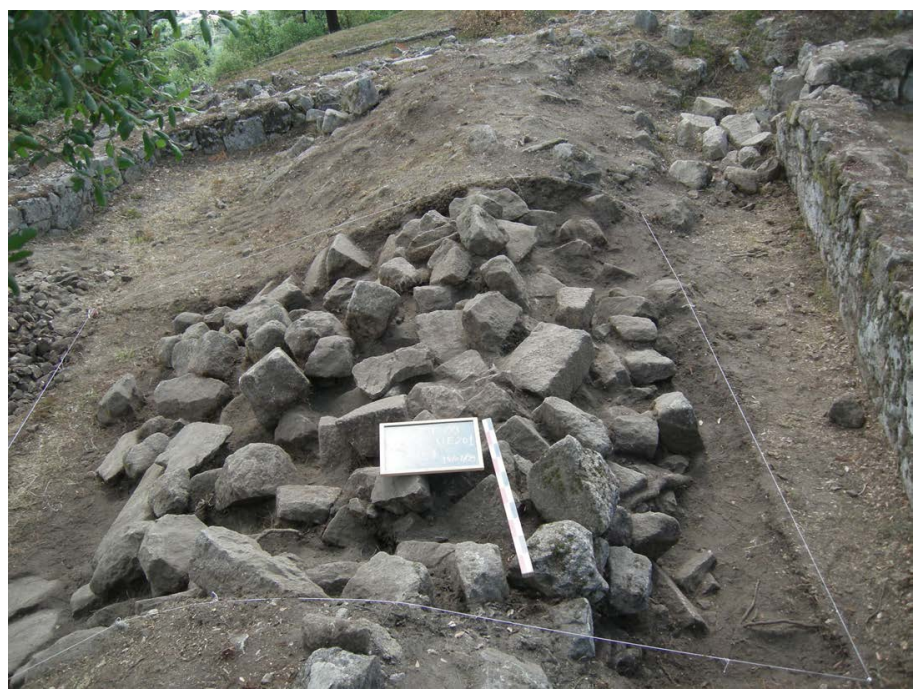

Figura 6. Aterro do século XIX (UEs 200, 201 e 202) registado na sondagem 97V.

b) Uma vala de saque de um lajeado do pátio (definida pelo interface UE -216 e preenchida pelas UE's 204, 208 e 209), que pode ter sido efetuado no decurso das escavações de Martins Sarmento, ou tratar-se mesmo de um saque feito em momento anterior;

c) Pavimento do pátio (UE 203) feito com lajes de média dimensão e de aparelho poligonal, idêntico aos pavimentos de outros pátios e de algumas ruas do povoado (Figura 7). Nesta atividade integrámos alguns níveis de preparação deste lajeado (UE’s 205, 206, 207 e 218). Foram recolhidas nestas camadas de preparação, além das cerâmicas características do final da Idade do Ferro, vários fragmentos de cerâmica comum romana, bem como de ânfora Haltern 70; 


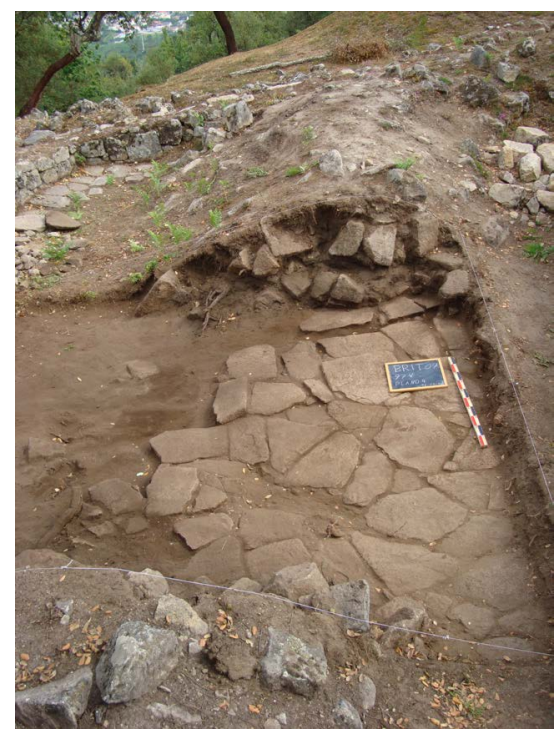

Figura 7. Lajeado (UE 203) registado na sondagem 97V, sob a camada de aterro resultante de anteriores escavações.

d) Conjunto de várias camadas sedimentares, interpretadas como um extenso contexto de nivelamento (UE's 210, 211, 212, 213, 214 e 219), nas quais também se recolheu cerâmica do período Alto-Imperial. De notar que este nivelamento atingiu o substrato geológico;

e) Duas camadas (UE's 217 e 220), sobrepostas pelo referido nivelamento, que continham apenas cerâmica da Idade do Ferro, associadas a uma estrutura de combustão (UE 215, Figura 8).

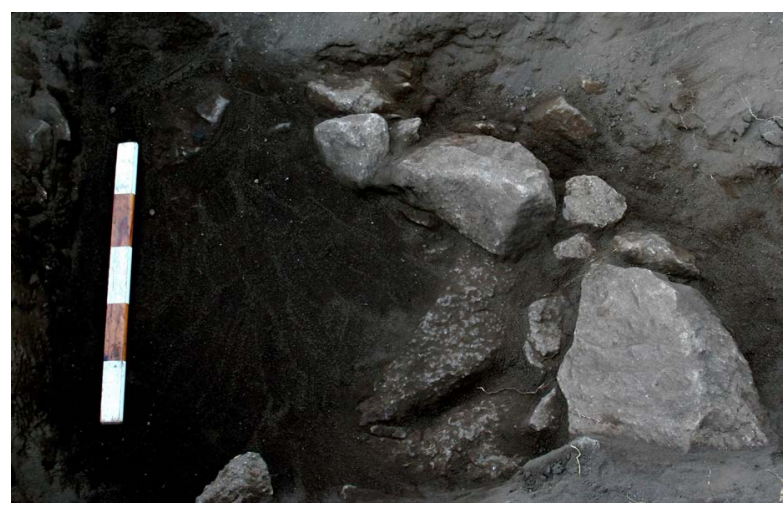

Figura 8. Estrutura de combustão (UE 215), localizada na sondagem 97V. 
Face ao exposto, a escavação desta sondagem, cuja decapagem atingiu o substrato geológico (Figura 9) revelou algumas surpresas. Em primeiro lugar, a identificação de vários elementos arquitetónicos entre o amontoado de pedras que formavam o aterro do século XIX. Entre estes elementos destaca-se uma prisão de gado que, curiosamente, tinha sido fotografada in situ por Martins Sarmento (Figura 10), após o que acabou por ir parar ao aterro. Destaca-se também um bloco afeiçoado, que terá integrado uma parede, com uma epígrafe muito erodida, na qual se lê o nome Avscvs $^{13}$ (Figura 11). Em segundo lugar, a própria existência do pavimento lajeado. Desconhecia-se, de facto, que tipo de pavimento teria tido este pátio, tendo em conta a sua configuração atípica em relação às restantes unidades habitacionais. Em terceiro lugar, a existência de uma estrutura de combustão prévia à construção deste pátio, sem que se tenha detetado qualquer outra construção, que presumimos totalmente arrasada, ou mesmo inexistente.

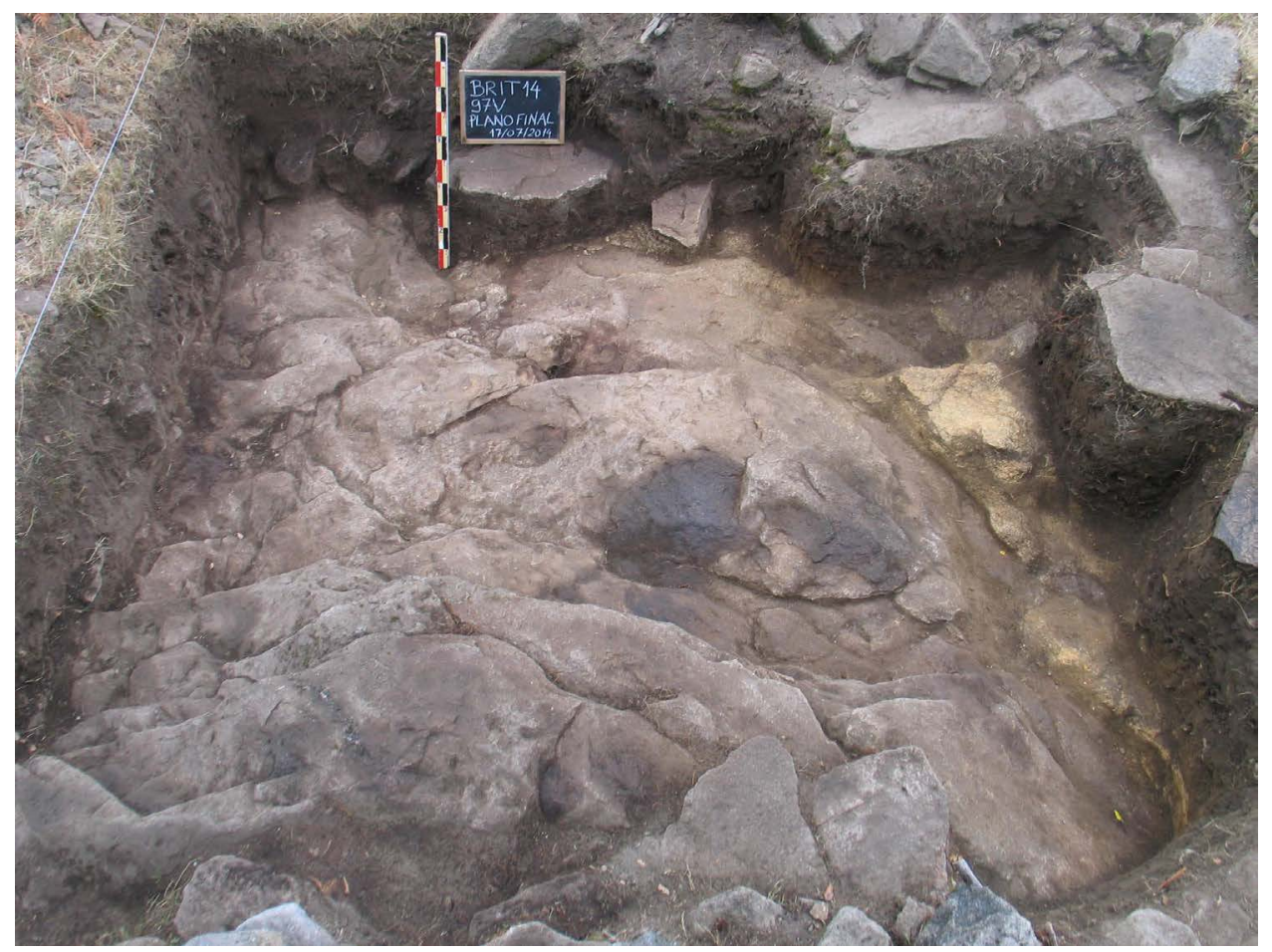

Figura 9. Plano final da sondagem $97 \mathrm{~V}$, mostrando a rocha-mãe, que se encontrava recoberta por estratos de regularização.

${ }^{13}$ Interpretação epigráfica de Armando Redentor, que observou a peça pouco depois da sua descoberta. Aqui deixamos o nosso reconhecimento. 


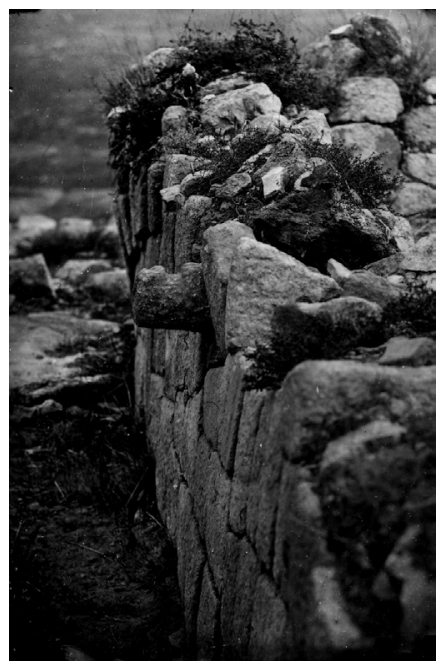

Figura 10. Prisão de gado colocada sobre um muro, no século XIX. Objeto reencontrado na campanha de 2009, na "Casa de Avscvs". Fotografia de Francisco Martins Sarmento. Coleção da SMS.

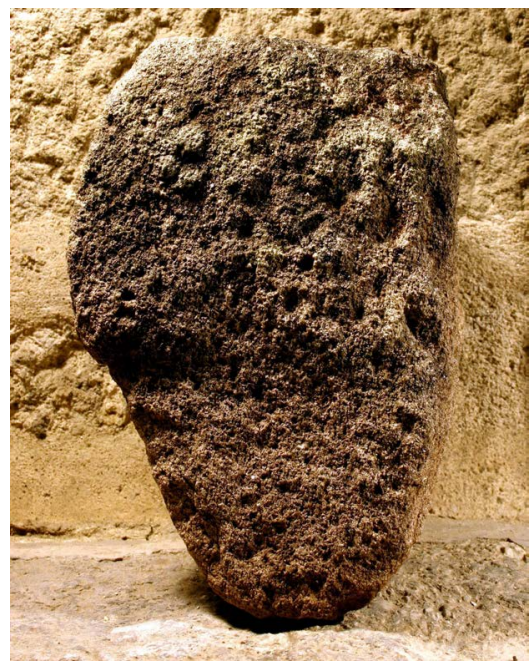

Figura 11. Elemento arquitetónico com epígrafe latina: Aus[ci?] (REDENTor, 2011, vol. II: 133). Fotografia de Armando Redentor.

A sondagem 99V foi aberta numa área abrangendo o interior de um dos compartimentos que rodeavam o pátio, precisamente o compartimento fundeiro, cujo acesso se encontrava centralizado em relação ao pátio (Figura 12). Esta sondagem 
abrangeu também uma pequena parte exterior ao compartimento em questão. Foram registadas as seguintes atividades estratigráficas por ordem de escavação:

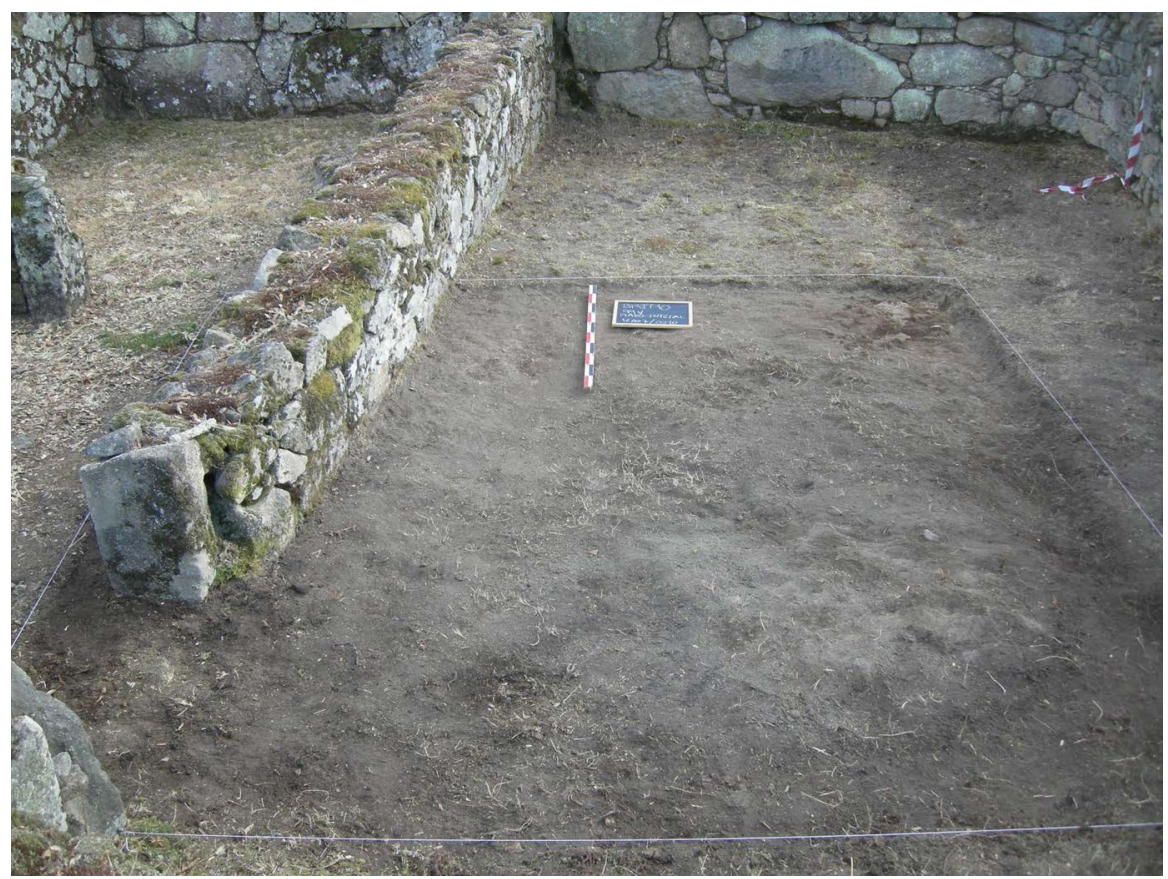

Figura 12. Plano inicial da sondagem $99 \mathrm{~V}$, localizada no interior de um compartimento da "Casa de Avscvs", abrangendo a porta que abre para o pátio.

a) Uma fina camada humosa (UE's 400, 401, 402 e 407) que cobria os vestígios do pavimento interior original. Idêntico contexto foi identificado na área exterior ao compartimento (UE's 403 e 408);

b) Pavimento interior (UE's 409, 411, 413 e 415), feito com argamassa de saibro e argila, conservando vários trechos da superfície original (Figura 13), bem como, embutido na argamassa, uma possível base de poste (UE 410).

A preparação deste pavimento era bastante profunda, cobrindo diretamente a rocha em vários locais, bem como a vala de fundação da parede abrangida pela sondagem (UE 404). A superfície do pavimento não era decorada, verificando-se uma ligeira inclinação do piso na direção da porta do compartimento. Foram recolhidos neste contexto vários fragmentos de cerâmica da Idade do Ferro, bem como de cerâmica comum romana; 


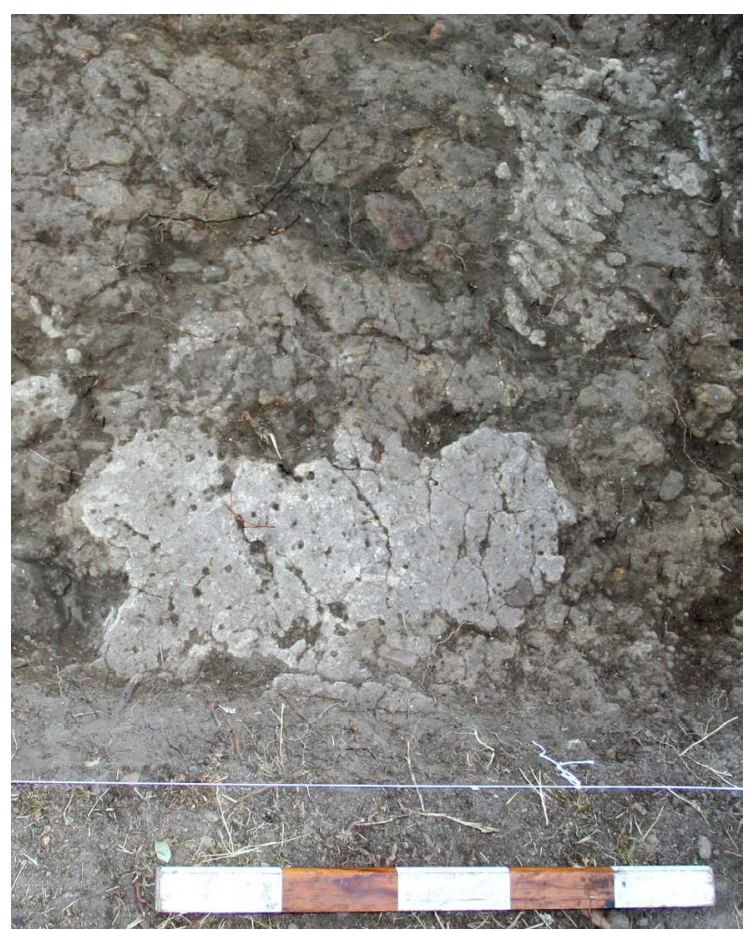

Figura 13. Superfície superior do pavimento (UE 409) detetado na sondagem 99V, na campanha de 2010.

c) Pavimento exterior (UE 412) que, curiosamente, não era um lajeado, mas um pavimento em argamassa idêntico ao do espaço interior;

d) Um contexto sedimentar (UE 414) que surgiu por debaixo da preparação do pavimento interior, em contacto com o substrato geológico, interpretado como um nível de regularização. Neste contexto apareceu uma metade de mó giratória, que parece ter sido “atirada” para o entulhamento;

e) Idêntico contexto sedimentar (UE 416) por debaixo do pavimento exterior, mas cuja escavação não foi terminada por impossibilidade logística;

f) Construção, desde a rocha, dos diferentes muros que formam o compartimento (UE's 404, 405 e 406);

g) Um considerável corte do afloramento rochoso (UE 417), que implicou o aplanamento da rocha para a sua utilização parcial como pavimento do próprio compartimento (Figura 14), bem como o corte para a vala de fundação do muro UE 404. 


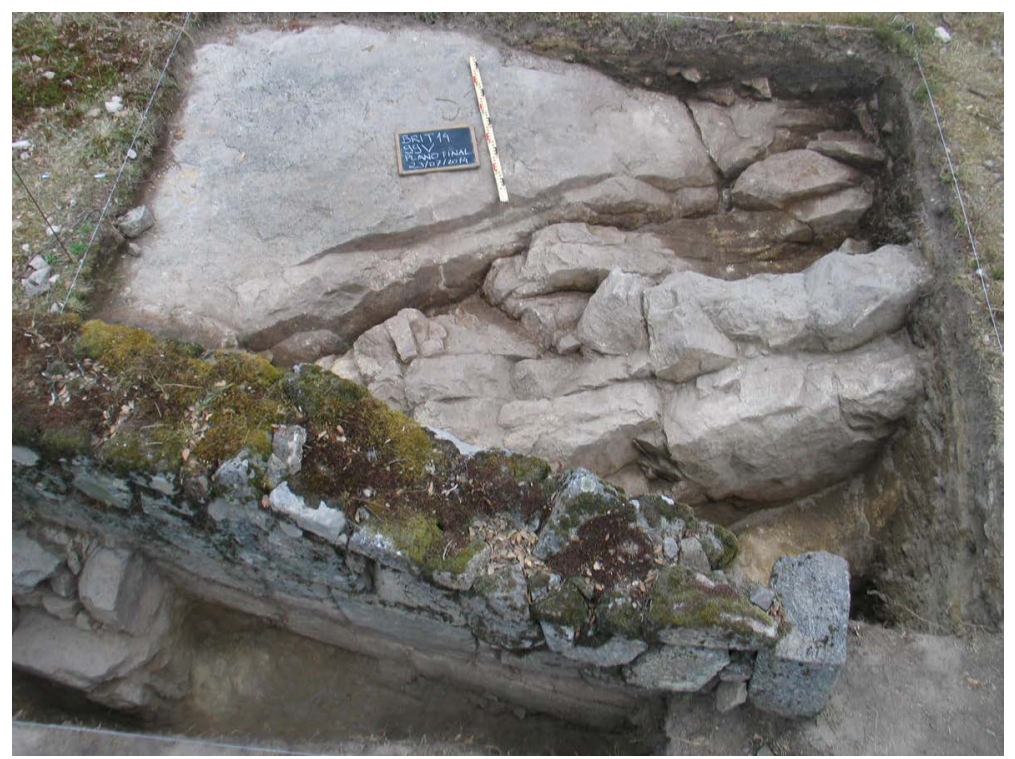

Figura 14. Plano final da sondagem 99V. Distingue-se o corte (UE -417) efetuado para implantação do muro do compartimento (UE 404), bem como uma área de rocha aplanada, que terá sido usada como pavimento.

A escavação desta sondagem não revelou, propriamente, dados inesperados, além do facto de o pavimento lajeado do pátio não ter sido feito até ao limite da parede fundeira, o que revela a existência de uma zona coberta, ao fundo do pátio, com um pavimento em saibro.

Relativamente aos materiais recolhidos, o espólio cerâmico apresenta-se, em geral, bastante fragmentado. Este fator explica-se, em grande medida, pela circunstância de se terem escavado, maioritariamente, níveis de revolvimento resultantes, por um lado, das escavações do século XIX, ou saques anteriores, por outro, da existência de várias camadas de regularização, acumuladas aquando da construção da unidade doméstica. Ou seja, praticamente não foram detetados níveis de ocupação, mas um conjunto de estratos diretamente relacionados com a construção da casa. Na verdade, apenas a estrutura de combustão detetada na sondagem 97V pode ser associada a um contexto de ocupação prévia deste espaço.

Os materiais recolhidos consistem em cerâmicas do final da Idade do Ferro (panelas de asa interior, potinhos, púcaros, tigelas e talhas), com alguns exemplares decorados, correspondentes à fase enquadrável entre os finais do século II a. C. e o 
século I a. C. ${ }^{14}$, mas misturados com cerâmicas datáveis de um contexto posterior. Foram recolhidos fragmentos de ânfora Haltern 70, como é habitual em estratos escavados na Citânia de Briteiros, cuja importação se iniciou a partir de meados do século I a. C. ${ }^{15}$. Foram recolhidos vários exemplares de cerâmica comum romana, correspondente ao período que medeia entre os finais do século I a. C. e o século I d. C. ${ }^{16}$. Destaca-se aqui um fundo de prato (Figura 15) recolhido num nível superficial da sondagem 99V, acima do pavimento original, o que pode dar uma ideia dos materiais existentes nos níveis de ocupação da casa, removidos no século XIX.

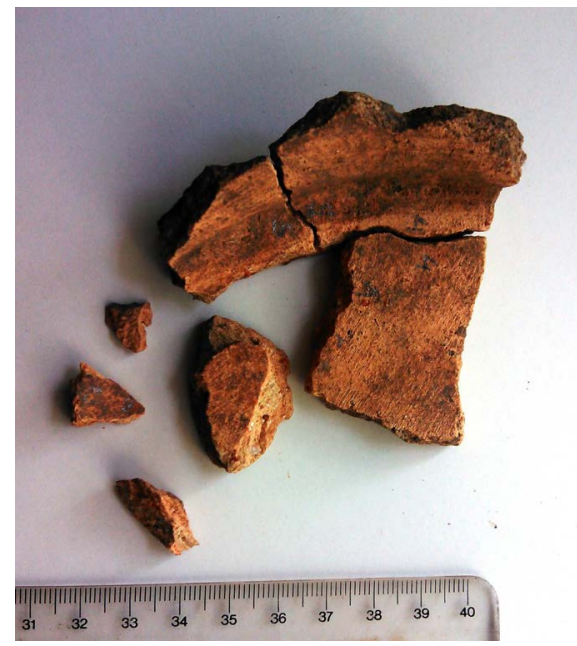

Figura 15. Fragmentos de prato de cerâmica romana de fabrico comum (achado 1, UE 407), recolhidos no interior do compartimento, na sondagem $99 \mathrm{~V}$.

Finalmente, foram recolhidos quatro fragmentos de Terra Sigillata (Figura 16), nomeadamente um fragmento de produção itálica e três fragmentos de produção hispânica (uma forma Dragendorff 24/25). Todos estes quatro fragmentos são provenientes dos níveis de aterro do século XIX, assinalados na sondagem 97V.

Foi também recolhida uma única moeda, um asse Alto-imperial, que se encontrava no enchimento da vala de saque do lajeado, também na sondagem 97V. Há ainda a assinalar a recolha de vários objetos metálicos, como dois alfinetes em

\footnotetext{
${ }^{14}$ MARTINS, M. (1990): O Povoamento Proto-histórico e a Romanização..., op.cit., pp. 155-163; SILVA, A. (2007): A Cultura Castreja no Noroeste de Portugal. Paços de Ferreira: Câmara Municipal de Paços de Ferreira, pp. 189201.

15 MORAIS, R. (2007): Materiais Arqueológicos III. A cerâmica romana. Relatório da unidade curricular. Braga: Instituto de Ciências Sociais da Universidade do Minho, pp. 142-143.

${ }^{16}$ MARTINS, M. (1990): O Povoamento Proto-histórico e a Romanização..., op.cit., pp. 172-73.
} 
bronze e vários fragmentos indeterminados de ferro, bem como, a nível de material orgânico, uma considerável quantidade de bolotas carbonizadas, nos níveis associados à estrutura de combustão existente por debaixo do lajeado do pátio.

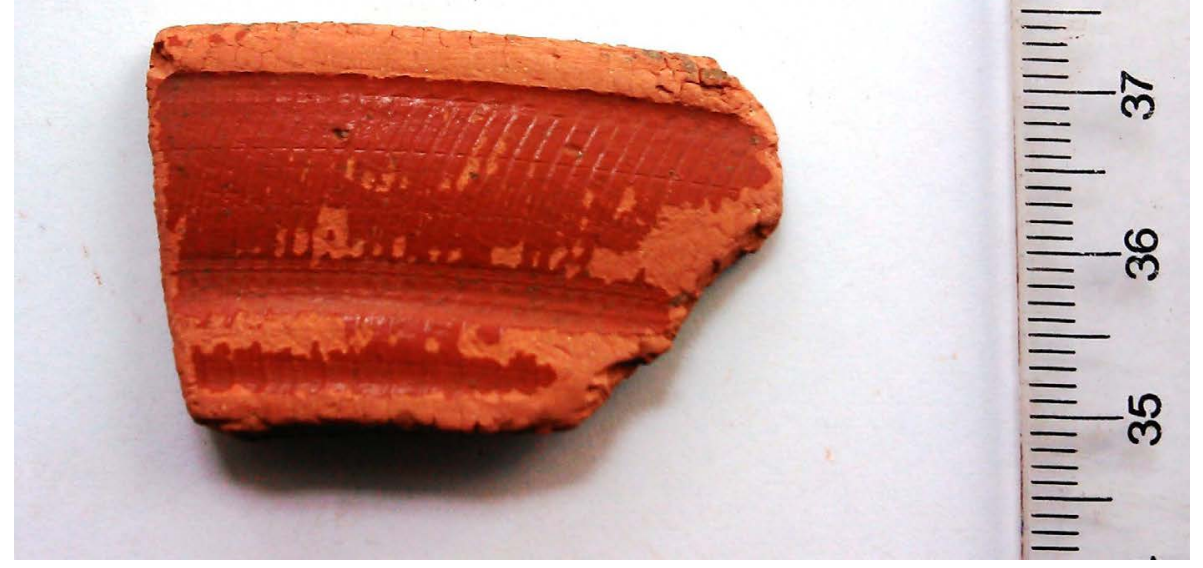

Figura 16. Fragmento de bordo de taça em Terra Sigillata de produção hispânica (sondagem 97V, UE 204).

\section{UMA CASA CARACTERÍSTICA DA TRANSIÇÃO DA ERA}

Uma síntese dos resultados desta duas sondagens, cruzados com os dados anteriormente obtidos pela escavação da sondagem 97T, permitem formular os seguintes raciocínios.

O espaço atualmente ocupado pela unidade habitacional $n^{0} 3$, do Sector 7, teria sido, eventualmente, um espaço habitacional com uma configuração diferente no século I a. C. Deste espaço resta-nos uma "estranha” estrutura de combustão, que aparenta ter sido uma fogueira exterior. Resta também o alinhamento que delimitava o espaço a Sudoeste, edificado no momento do traçado e construção da via pública, ainda na primeira metade do século I a. C. Não se identificaram, neste ponto, estratos arqueológicos mais antigos. Nos finais do século I a. C., ou inícios do século I d. C., cronologia relativa aconselhada pelos materiais exumados, acima descritos, constrói-se a unidade doméstica com a configuração que lhe conhecemos. O proprietário deste 
espaço, um muito provável membro da aristocracia local, vai seguir os padrões arquitetónicos que constituíam então uma novidade e que correspondiam às conceções romanas da casa com pátio. Para o efeito vai orientar a rede murária do conjunto de forma perpendicular ao alinhamento existente, a parede que delimitava o espaço da rua pública. Pela mesma altura, e por circunstâncias não apuradas, o nível de pavimentação da rua foi substituído por uma nova pavimentação, a uma cota superior (Figura 17).

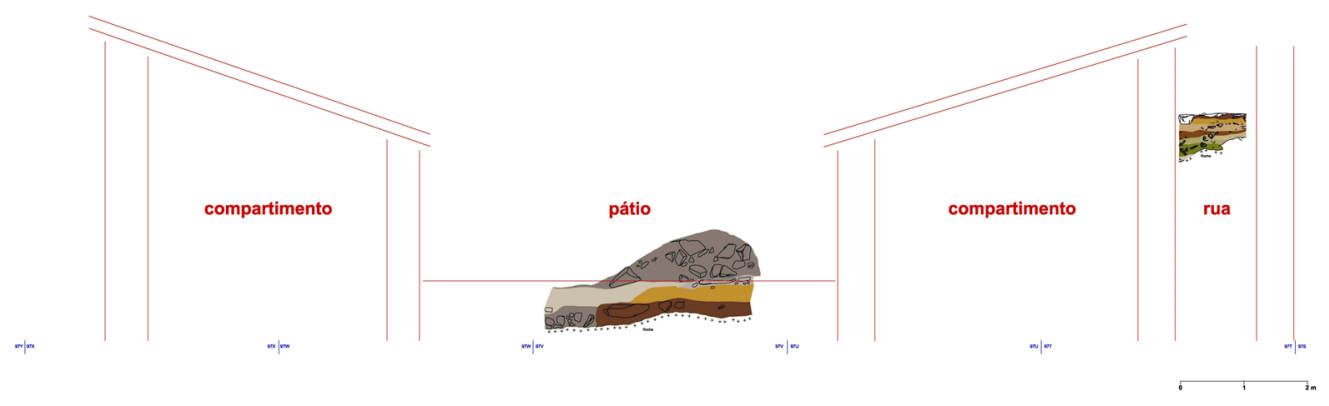

Figura 17. Alinhamento dos perfis Sudeste das sondagens 97V e 97T, com marcação dos limites dos compartimentos da "Casa de Avscvs" e dos limites da via pública.

Este novo espaço habitacional terá uma entrada, aparentemente única, a partir da via pública, com uma soleira bem visível (Figura 18), que dava acesso a um vestíbulo coberto. Deste vestíbulo passava-se a um pátio interior, a céu aberto, com pavimento lajeado. Embora sejam presumíveis várias funções de carácter doméstico para o pátio, a presença de pelo menos uma "prisão de gado" sugere que animais seriam, temporária ou permanentemente, mantidos neste espaço, o que não deixa de suscitar uma certa estranheza. No limite fundeiro do pátio existiria uma pequena zona coberta, o que se verifica pelo término do lajeado antes da parede, tendo-se identificado um espaço pavimentado com argamassa, que poderá corresponder a um pequeno alpendre. O compartimento fundeiro pode ter sido uma zona de triclínio, tratando-se de uma hipótese bastante conjetural, a partir dos materiais recolhidos nas camadas de revolvimento. Todos os compartimentos em redor do pátio seriam cobertos com uma estrutura de madeira recoberta a tegulae, cujos fragmentos estão presentes nos aterros do século XIX e são descritos como abundantes nos diários de Martins Sarmento. Naturalmente, as paredes interiores seriam rebocadas e pintadas, o que já não seria uma novidade neste momento cronológico. 


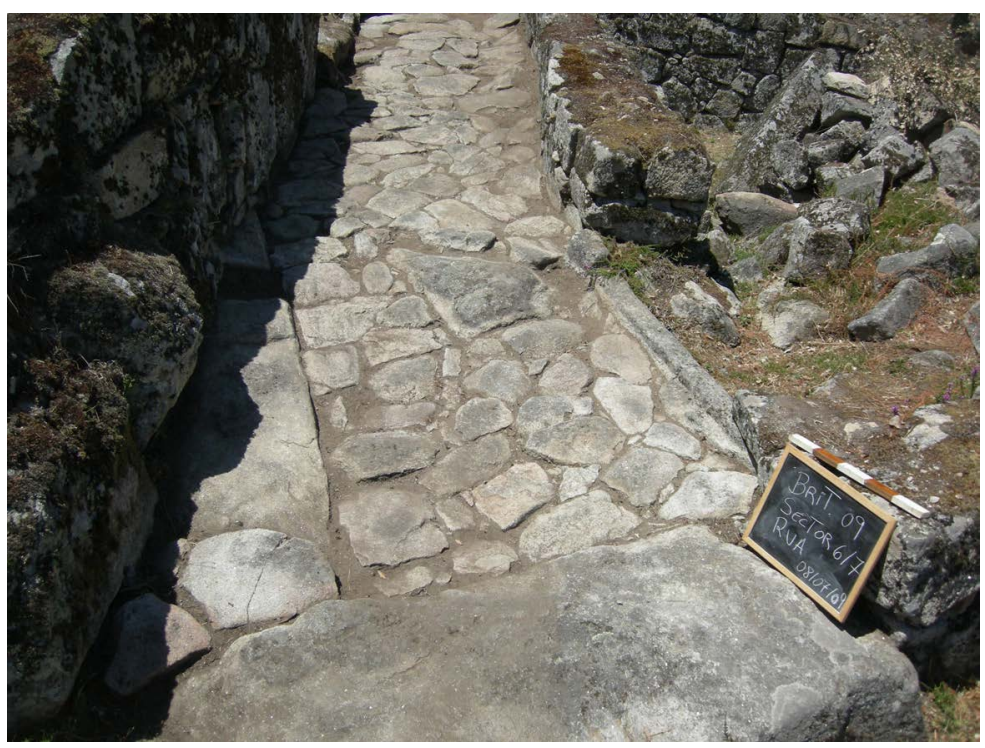

Figura 18. Soleira da porta de acesso à "Casa de Avscvs" a partir da via pública.

O proprietário desta casa, que poderia ter-se chamado Avscvs, seria um indígena, hipótese reforçada pela origem local deste nome ${ }^{17}$. Mas um indígena membro da aristocracia local que, negociando com o poder romano, quiçá enriquecendo com ele, adota a escrita alfabética latina ao gravar o seu nome na parede da casa, adota o numerário, possuindo dinheiro, e adquire vistosas louças finas importadas, que conhecemos como Terra Sigillata.

Acima de tudo, a sua sofisticação é evidenciada por construir uma casa ao estilo romano, quiçá inspirada nas novas construções de Bracara Augusta. Sofisticação que não é, no entanto, suficiente para impedir a manutenção de animais no pátio da sua casa, pretendente a elegante peristilo.

Os fragmentos de terra sigillata provêm exclusivamente de níveis de aterro do século XIX. Serão, no entanto, e muito provavelmente, oriundos deste espaço, dos seus níveis de utilização e abandono. Pese embora o reduzido número de fragmentos, estes materiais, particularmente as produções hispânicas, indiciam uma cronologia de utilização que atingirá, no máximo, o século II d. C. Tal é o término temporal que, até à data, temos definido para a ocupação da Citânia de Briteiros.

${ }^{17}$ REDENTOR, A. (2011) A Cultura Epigráfica no Conventvs Bracaravgvstanvs (Pars Occidentalis). Percursos pela Sociedade Brácara da época Romana. Dissertação de Doutoramento. Coimbra: Faculdade de Letras da Universidade de Coimbra, vol. II, pp. 132-133. 


\section{CONCLUSÃO}

Após estas breves reflexões, necessariamente preliminares tendo em conta a limitação espacial da área intervencionada, resta-nos referir duas considerações finais. A primeira visa aconselhar, entre futuros trabalhos de gabinete, um estudo comparativo da "Casa de Avscvs" com a arquitetura doméstica de Bracara Augusta, particularmente no período fundacional da cidade romana. Este estudo deverá ter em conta a padronização das dimensões dos compartimentos, a sua repartição funcional, a altura das paredes e os materiais de construção utilizados.

A segunda visa adequar um pouco os conceitos de "pré-romano" e "romano". Apesar de, neste caso específico, a Romanização se encontrar praticamente diante dos nossos olhos, o mesmo não se passa com a maioria das unidades habitacionais que eram habitadas neste oppidum de Briteiros na transição da Era, momento em que a densidade máxima de ocupação do povoado já tinha sido atingida, sem que, no século I d. C. a maioria das unidades familiares tenha sido substituída por este modelo de casa, de "tipo domus". Com efeito, além da casa que aqui descrevemos, existem apenas mais três exemplos claros na área escavada do povoado. Não existe, portanto, um momento cronológico específico em que deixam de se construir ou habitar casas circulares, e se começam a habitar "casas romanas”. Existe, sim, um longo processo de mudança cultural, a ritmos necessariamente diferentes, condicionados pelos territórios, pelos sítios e pelas pessoas que os habitavam. Falamos, portanto, das mesmas pessoas, das mesmas comunidades, que a dada altura começam a adquirir novos hábitos, novos gostos e o que conhecemos como uma cultura provincial do Império Romano.

\section{BIBLIOGRAFIA}

AYÁN VILA, X. (2013). “Todo queda en casa: espacio doméstico, poder y división social en la Edad del hierro del NW de la Península Ibérica”. En Gutiérrez, S. y Grau, I. (eds). De la estructura doméstica al espacio social. Lecturas arqueológicas del uso social del espacio. Alicante: Publicaciones Universidad de Alicante, pp. 39-56.

CARDOZO, M. (1949). "Escavações na Citânia de Briteiros. Relatório da campanha de 1949”. Revista de Guimarães, 59 (3-4), pp. 406-414.

CARDOZO, M. (1996). Citânia de Briteiros e Castro de Sabroso. Notícia descritiva. Guimarães: Sociedade Martins Sarmento.

CRUZ, G. (2015). "O surgimento do espaço urbano no Noroeste da Ibéria. Uma reflexão sobre os oppida pré-romanos”. En Martínez Peñín, R. y Cavero Domínguez, G. (eds). Evolución de los espacios urbanos y sus territorios en el Noroeste de la Península Ibérica. León: 
Instituto de Estudios Medievales de la Universidad de León, Unidade de Arqueologia da Universidade do Minho, pp. 403-424.

CRUZ, G. ANTUNES, J. (2010). “Citânia de Briteiros. Notícia dos trabalhos arqueológicos (2007-2010)”. Revista de Guimarães, 119/120, pp. 221-237.

GONZÁLEZ-RUIBAL, A. (2006-07): “Galaicos. Poder y Comunidad en el Noroeste de la Península Ibérica (1200 a.C. - 50 d.C.)”. Brigantium, 18-19. A Coruña: Museo Arqueológico e Histórico da Coruña.

LEMOS. F. CRUZ, G. (2005-06). “Trabalhos arqueológicos na Citânia de Briteiros. Campanhas de 2005 e 2006”. Revista de Guimarães, 115/116, pp. 11-50.

LEMOS. F. CRUZ, G. (2006). “Citânia de Briteiros. Programa de Investigação e Valorização do Monumento”. Fórum (separata), volume 39, Unidade de Arqueologia da Universidade do Minho, Braga.

LEMOS. F. CRUZ, G. (2007). “Citânia de Briteiros: trabalhos arqueológicos recente”. AlMadan Online / Adenda Electrónica. II ${ }^{a}$ Série, 15, VI, pp. 31-36.

LÓPEZ MARCOS, M. ÁLVAREZ GONZÁLEZ, Y. LÓPEZ GONZÁLEZ, L. F. (2011). “Arquitectura defensiva en el Castro de Castromaior (Lugo). Análisis de las técnicas constructivas en el acceso al recinto central del poblado”. Arqueología de la Arquitectura, 8, pp. 47-63.

MARTINS, M. (1990): “O Povoamento Proto-histórico e a Romanização da Bacia do Curso Médio do Cávado.” Cadernos de Arqueologia. Série Monografias, volume 5. Braga: Unidade de Arqueologia da Universidade do Minho.

MORAIS, R. (2007): Materiais Arqueológicos III. A cerâmica romana. Relatório da unidade curricular. Braga: Instituto de Ciências Sociais da Universidade do Minho.

REDENTOR, A. (2011) A Cultura Epigráfica no Conventvs Bracaravgvstanvs (Pars Occidentalis). Percursos pela Sociedade Brácara da época Romana. Dissertação de Doutoramento. Coimbra: Faculdade de Letras da Universidade de Coimbra.

RODRÍGUEZ MARTÍNEZ, R.. ABOAL FERNÁNDEZ, R. CASTRO HIERRO, V. CANCELA CEREIJO, C. AYÁN VILA, X. (2011). "Una posible factoría prerromana en el Noroeste. Primeras valoraciones de la intervención en el Campo de A Lanzada (Sanxenxo, Pontevedra)”. Férvedes: Revista de Investigación, volume 7, pp. 159-168.

SILVA, A. (2007): A Cultura Castreja no Noroeste de Portugal. Paços de Ferreira: Câmara Municipal de Paços de Ferreira. 